\title{
NUTRITIONAL HABITS AND PHYSICAL ACTIVITY OF STUDENTS
}

\author{
P. Petkov* \\ Trakia University, Stara Zagora, Bulgaria
}

\begin{abstract}
A survey of 176 students (women) in the first and second course of all specialties from the Faculties of Economics, Agriculture and Veterinary Medicine at Trakia University, Stara Zagora, was conducted. The aim of the study was to identify the food habits and the physical activity of the students. Theoretical analysis, questionnaire, graphical analysis, comparative analysis of relative shares and alternative analysis were applied to achieve this goal. Anonymous survey was conducted to collect quantitative information on the eating habits and physical activity of students from Trakia University. The questionnaire included 22 questions. Analysis of the results displayed that students do not eat healthily due to lack of time, spend most of the day sitting and have insufficient motor activity. The survey data led to the assumption that the students' awareness of the benefits of healthy eating and increasing their physical activity has to be increased.
\end{abstract}

Key words: healthy eating, physical activity, body weight

\section{INTRODUCTION}

A High risk of chronic diseases are common for our nation during the past few years.Young people are increasingly abusing the consumption of unhealthy foods and beverages, they are constantly sitting in front of the television and computers, excersing and being less active. This leads to an unhealthy lifestyle and immobilization, which is the cause of serious illnesses such as diabetes, spinal distortion, obesity and others. The number of deseases related to nutrition and low motor activity is growing constantly according to Dyakova $(1,2)$. A study, which is published in the journal "Tne Lancet" (3) says bad natrition is the cause of every fifth death in the world. In 2017, around 11 milion people became victims of fast food, sweets and other unhealthy foods.

The nutrition of the Bulgarian population is related to hyper-energy, hyperlipidemia and high salt consumption according to Angelowa and Dyakova $(4,5)$. One of the main issues

\footnotetext{
*Correspondence to: Plamen Petkov, Trakia University, Stara Zagora, Bulgaria, e-mail: jo_team@abv.bg, GSM 0887881260
}

among the adolescents is obesity. Proper eating regime is essential for good health condition. According to Merdjanov (6), the presence of obesity in childhood depends on many factorsconsumption of unhealthy foods, an inactive lifestyle, hormonal imbalance and others.

In recent years Bulgaria is leading in classification of obese nations. The conscious continuous and incorrect eating mostly for girls leads to an increase in eating disorders. A number of studies show that workability of students can be increased with appropriate regime and rhythm of eating with a good balance of the main nutrients and enough amount of food (7-14)

Irrational and improper nutrition affects selfesteem and workability of students. The aim of the present study is to establish students habits at the Trakia University for healthy eating and motor activity in free time.

To accomplish the purpose we have set the following tasks:

1.To develop a survey

2.To create a survey research

3.To process and analyze the data of the survey research 


\section{METODS OF RESEARCH}

\section{Survey research}

2.Alternative analysis

The survey was produced during the summer semester of the academic year of 2018/2019. Contingent of the research are 202 female students of the ages between 17,20 years from Agreculture faculty, Veterinary medicine faculty and Faculty of Economics and Business Administration at Trakia University, Stara Zagora. The survey was anonymous. The survey contained 20 questions.

\section{ANALYSIS OF RESULTS}

After processing the data from the servey we received the following results:

To the question "How many times a day do you eat?" 4,55\% are eat once a day, 30,30\% twice, $43,94 \%$ three times, $9,09 \%$ four times, $9,09 \%$ five times and 3,03\% over five times a day. For comparison in 2011, a study by G. Dyakova on the same question, $3,9 \%$ are eat 1 time, $37,2 \% 2$ times, 3 times eat 42,4\%, 4 times 13,2\%, 5 and more than 5 times $3.3 \%$. According to many doctors and dieticians, it is best and most useful to eat in little portions around five and more times per day. As we can see from the answers to the question, only about $12 \%$ eat healthy. The results are presented graphically in Figure 1.

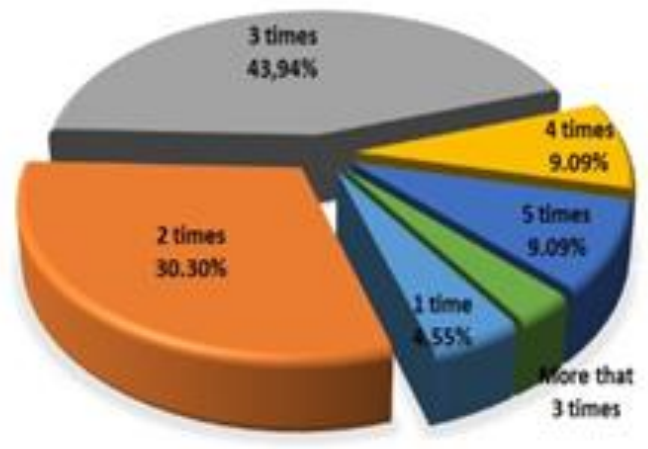

\section{Figure 1. Answer this question „How many times a day do you eat?"}

To the question "Do you consider you are eating healthy?", students who think they eat healthy are $30,30 \%$ and those who do not eat healthy are $69.70 \%$. For comparison in 2012, a study by G. Dyakova on the same question $36.1 \%$ answered positively and $63.9 \%$ responded with "No". Students, who think they eat healthy are decreasing. The reasons which the students indicated (Question „If you think you are not eating healthy what's the cause?") not to eat healthy are- lack of time $(56,06 \%)$, financial reasons $(28,79 \%)$, they don't like it $(9,09 \%)$ and they don't have a desire $(6,06 \%)$. The results are presented graphically in Figure 2.

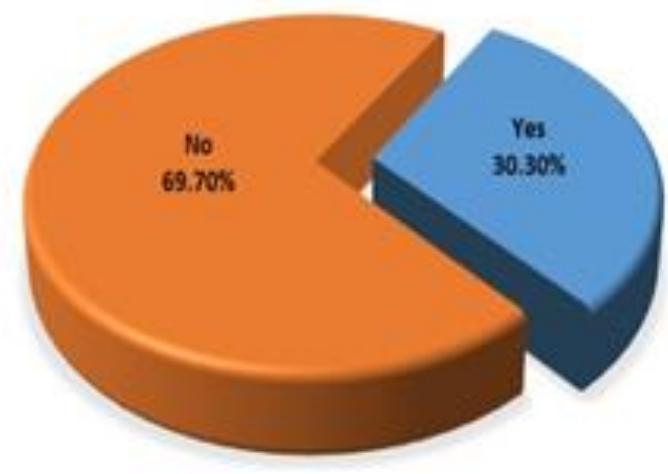

\section{Figure 2. Answer this question „Do you consider you eating healthy?"}

To the question" Do you have experience about healthy eating" $80,30 \%$ of students have sufficient knowledges of healthy eating and others $19,70 \%$ report that their knowledges are insufficient. The results are presented graphically in Figure 3. 


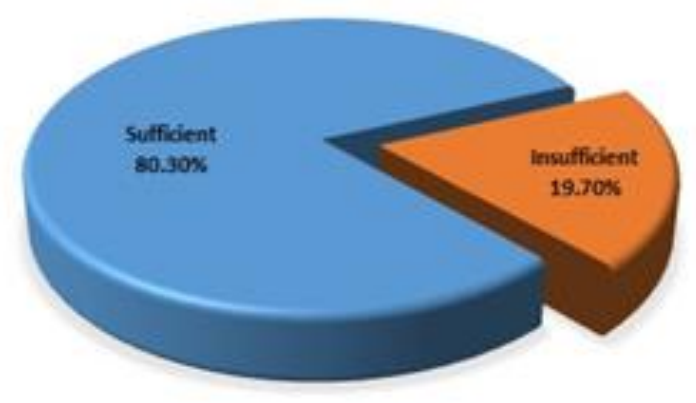

Figure 3. Answer this question „Do you have knowledge of healthy

To the question „How many fruits have you eaten during the last 30 days?" once a day they cosumed $27,27 \%$ of the students, twice a day $15,15 \%$, more than twice a day $13,64 \%$ and once in a few days $43,94 \%$. As can be see from the answers, the fruits are absent from daily menu by almost half of the students. To compare in 2017 a study by L. Borissov on the same question $33 \%$ had consumed fruits one in a few days and $38 \%$ once a day. There is a decrease in fruits consumption. The results are presented graphically in Figure 4.

\section{Figure 4. Answer this question „How many fruits have you eaten during the last 30 days?"}

To the question „How many vegetables have you eaten during the last 30 days" once a day they ate vegetables $34.85 \%$, twice a day $19.70 \%$, more than twice a day $21.20 \%$, and once in a few days $22.73 \%$. To compare in 2017 a study by L.
Borisov on the same question, $16 \%$ consume vegetables once in a few days, once a day $46 \%$ and twice a day $29 \%$. There is a slight increase in the consumption of vegetables. The results are presented graphically in Figure 5.

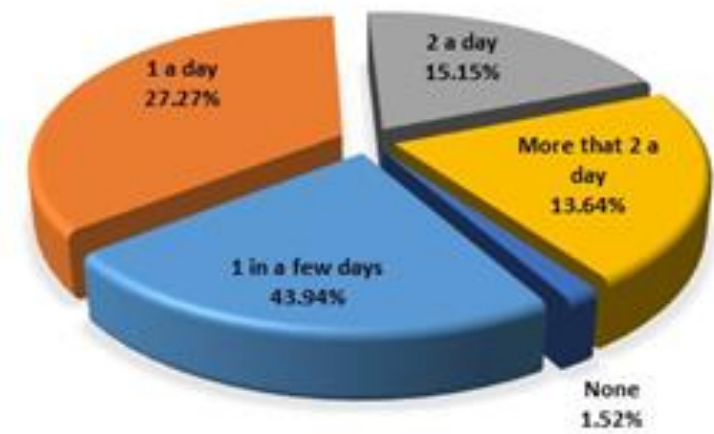

Figure 5. Answer this question „How many vegetables have you eaten during the last 30 days?"

To the question „How many times have you drunk soft drinks during the last 30 days" $46.96 \%$ of students do not consume soft drinks, $34,85 \%$ once in a few days, $10,61 \%$ consumed once a day, $4,55 \%$ twice a day and 3,03\% more than 2 times a day. For comparison, in 2017, a study by L. Borissov on the same issue, $53 \%$ did not consume soft drinks. There is an increase in the consumption. The results are presented graphically in Figure 6. 


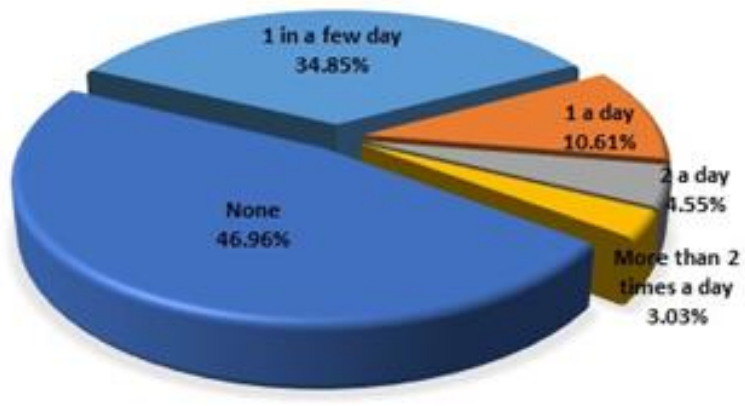

Figure 6. Answer this qustion „How many times have you drunk soft drinks during the last $\mathbf{3 0}$

days"?"

To the question „How many days have you consumed a "fast-food" during the last week?" $21.21 \%$ did not consume, $21.21 \%$ consumed one day, $18.19 \%$ two days, $18.18 \%$ three days, $12.12 \%$ every day, four, five and six days consumed 3,03\% of the students. For comparison in 2017 a study by L. Borisov on the same question, 56\% did not consume such a food. We are seeing a decrease in the percentage of students who have not ate "Fast Food". The results are presented graphically in Figure 7.

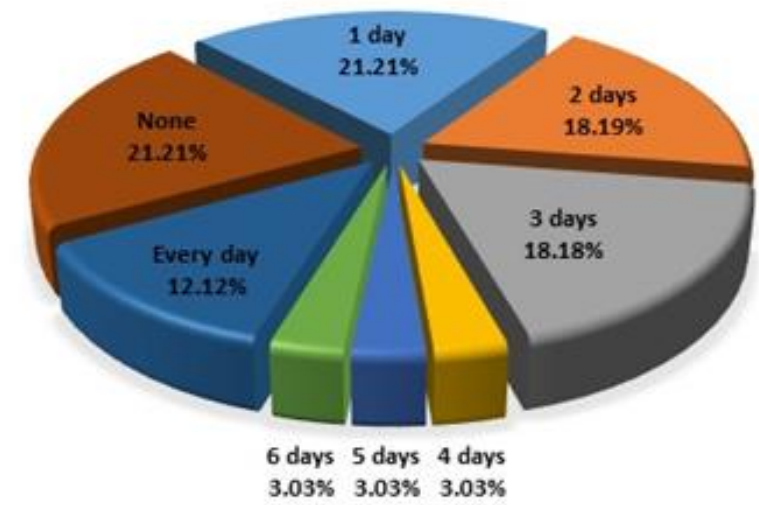

Figure 7. Answer this question „How many days have you consumed "fast-food” during the last week?"

To the question „What kind of food dominates in your daily menu" for $30,29 \%$ of students the meat and meat products predominate in their menu, $24,24 \%$ of them use pasta products, $13,64 \%$ of the dairy products, $10,61 \%$ of the vegetables, $9,09 \%$ of the sugar products and for others 12,13\% dominates „fast-food“, fruits, semi-manufactured products и soft drinks. For comparison in 2012 a study by P. Milanova on the same question meat is $18 \%, 5,10 \%$ are pasta products, $12,40 \%$ are vegetables, $21,30 \%$ are sugar products. There is an increase in the percentage of consumption of meat and pasta products and a decrease in the consumption of vegetables. The results are presented graphically in Figure 8.

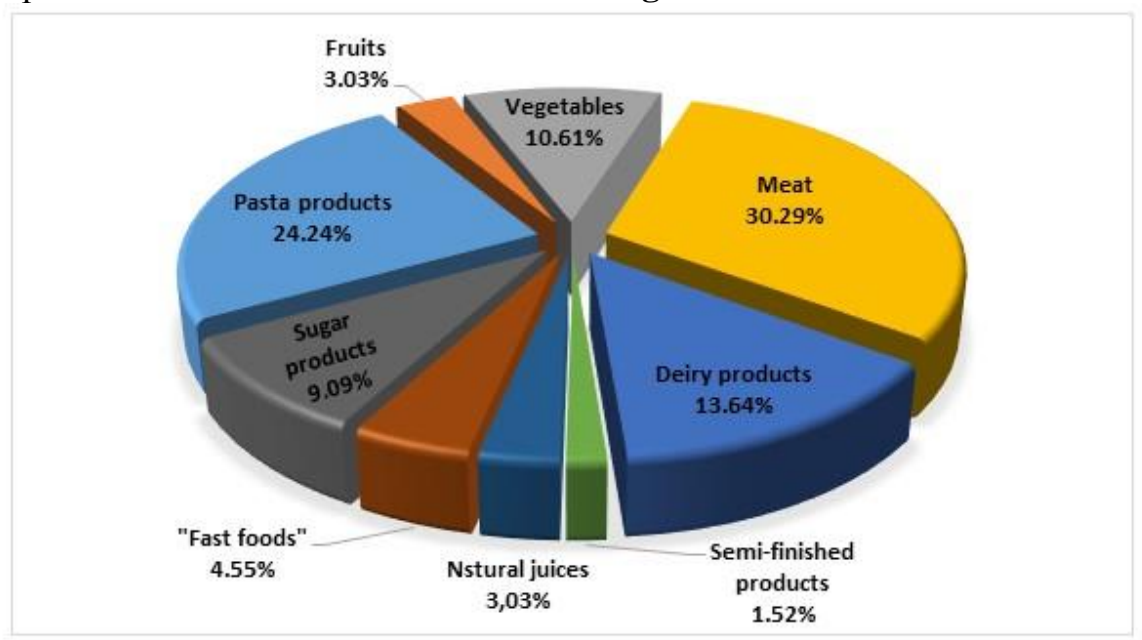

Figure 8. Answer this question „What kind of food dominates in your daily menu?“ 
To the question „Have you ever been 24 hours or more without food to lose weight?" $73.73 \%$ did not starve to lose weight and $27.27 \%$ responded positively. For comparison in 2012 a study by $\mathrm{P}$.
PETKOV P.

Milanova on the same question students from Berkovitsa $(7,33 \%)$ gave a positive answer. The results are presented graphically in Figure 9.

Figure 9. Answer this question „Have you ever been 24 hours or more without food to lose

weight?"

To the question „Have you ever used pills and dietary supplements for weight loss without prescription." $87.88 \%$ have not used and $12.12 \%$ have tried medicaments and supplements to reduce weight. For comparison in 2012 a study by $\mathrm{P}$. Milanova on the same question $4.67 \%$ answered positively. There is an increase in the percentage for the supplements. The results are presented graphically in Figure 10.

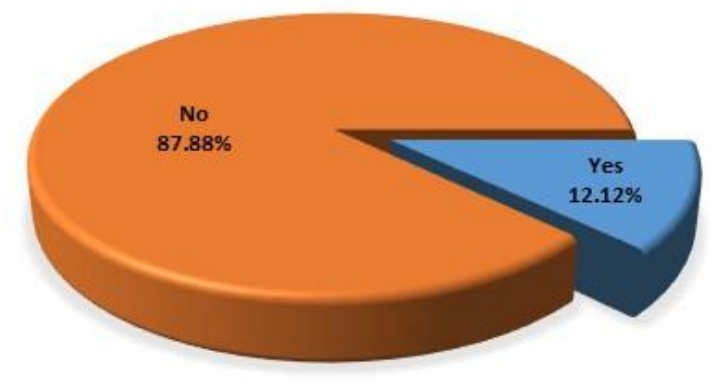

Figure 10. Answer this question „Have you ever used pills and dietary supplements for weight

\section{loss without prescription?“}

To the question „How do you describe your body weight?" $69.70 \%$ determine their weight as normal, $24.24 \%$ consider that they are above the norm and $6.06 \%$ are below the norm. For comparison in 2012, a study made by $\mathrm{P}$.
Milanova on the same issue, $74 \%$ describe their weight as normal and $12 \%$ above the norm. There is an increase in the percentage of those who are overweight. The results are presented graphically in Figure 11.

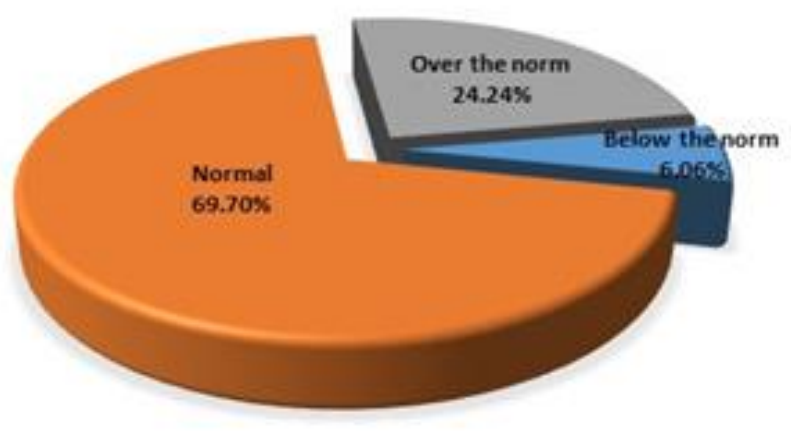

Figure 11 . Answer this question „How do you describe your body weight? 
To the question „Do you want to change your body weight?" $62,12 \%$ responded positive and $37,88 \%$ responded negative. For comparison in 2011, a research by G. Dyakova on the same question $67.3 \%$ answered "Yes" and $32.7 \%$ with "No". The results are presented graphically in Figure 12.

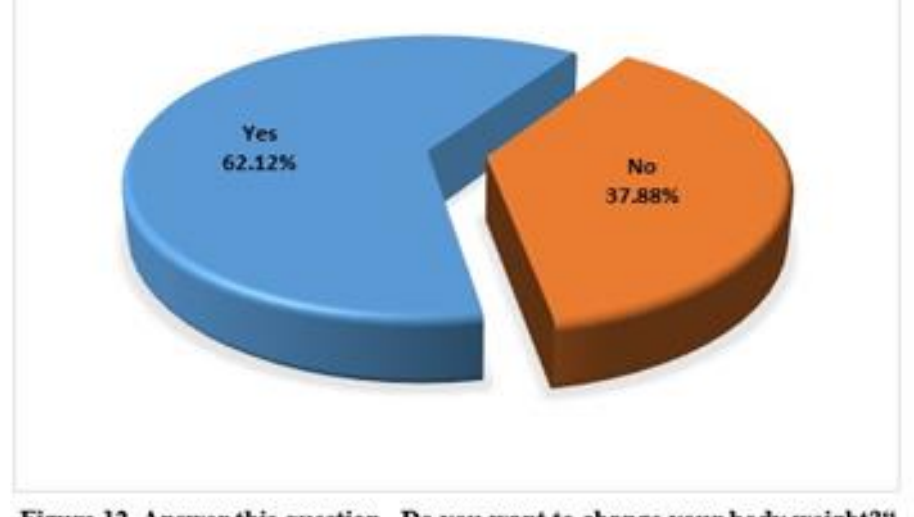

Figure 12. Answer this question „Do you want to change your body weight?*

To the question „Do you have the knowledge of keeping under control your body weight?" $65,15 \%$ consider that they have enough knowledge, $24,24 \%$ think that they have knowledge but they are not sufficient and $10,61 \%$ have no knowledge. For comparison, in
2011, a study by G. Dyakova on the same question, $26.2 \%$ had plenty knowledge, $57.9 \%$ was insufficient and $15.9 \%$ had no knowledge of keeping body weight. The results are presented graphically in Figure 13.

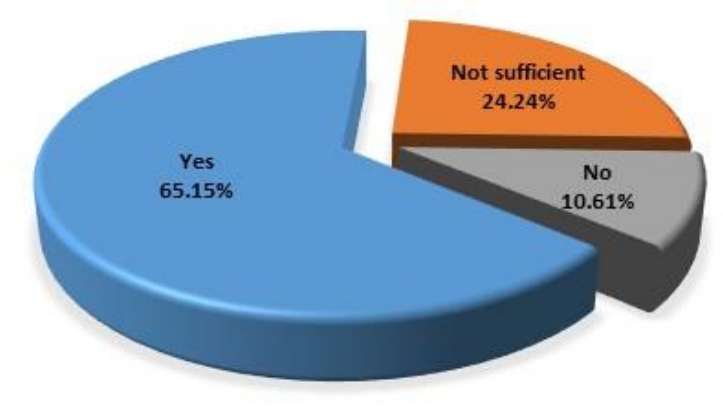

Figure 13 Answer this question „Do you have the knowledge of keeping under control

your body weight?“

To the question „How much a day do you spend sitting down usually?" $40.91 \%$ spend seated on average 5-6 hours a day, $24.23 \%$ 3-4 hours, $19.70 \%$ 7-8 hours, $1-2$ hours spend $7.58 \%$, $6.06 \%$ are sitting more than 8 hours a day and $1.52 \%$ less than an hour. For comparison, in
2017 a research by L. Borissov on the same question $50 \%$ spent sitting more than 5 hours, in 2019 the percentage of students spending sit more than 5 hours a day is $66.67 \%$. The results are presented graphically in Figure 14.

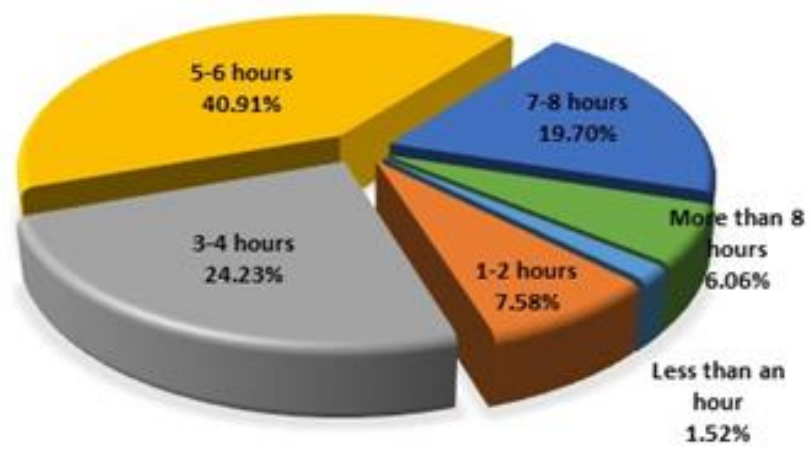

Figure 14. Answer this question „How much a day do you spend sitting down usually?" 
To the question „Do you practice physical exercises outside of the University?" $57.58 \%$ answer with "Yes" and $42.42 \%$ of students respond with "No". For comparison in 2011, a study by G. Dyakova on the same question, $33.9 \%$ of students are physically active outside of the university and $66.1 \%$ have given a negative answer. The results are presented graphically in
Figure 15. The biggest reason for the students not to practice physical exercises outside of the University is the lack of time $(83.33 \%)$ and others as a lack of desire $(4.55 \%)$, the lack of a base for practicing the preferred sport $(9.09 \%)$ and financial reasons $(3,03 \%)$. The results are presented graphically in Figure 15.

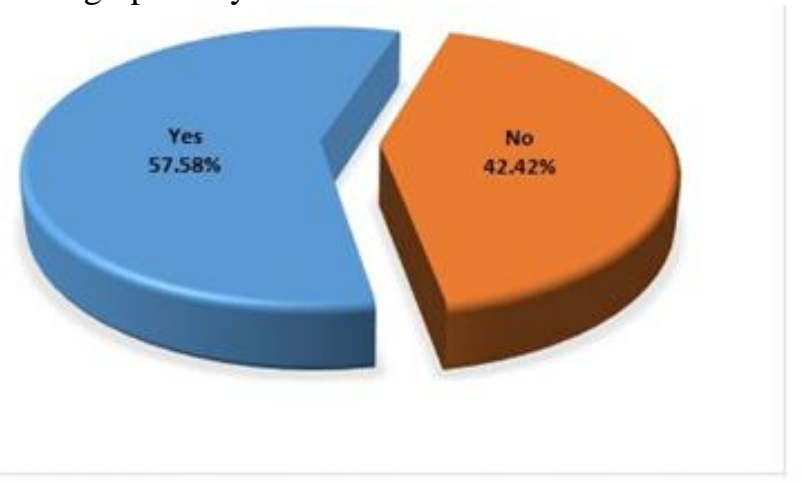

Figure 15. Answer this question „Do you practice physical exercises outside of the University?*

To the question „How many times a week you do physical exercises?" $43.94 \%$ are doing twice a week, $21.21 \%$ just once, $21.21 \%$ more than three times and $13.64 \%$ three times a week. For comparison, in a survey made by G. Dyakova in the same question, $40 \%$ indicated 1 time, 2 times $36.2 \%, 18.1 \% 3$ times and $5.7 \%$ more than 3 times. The results are presented graphically in Figure 16.

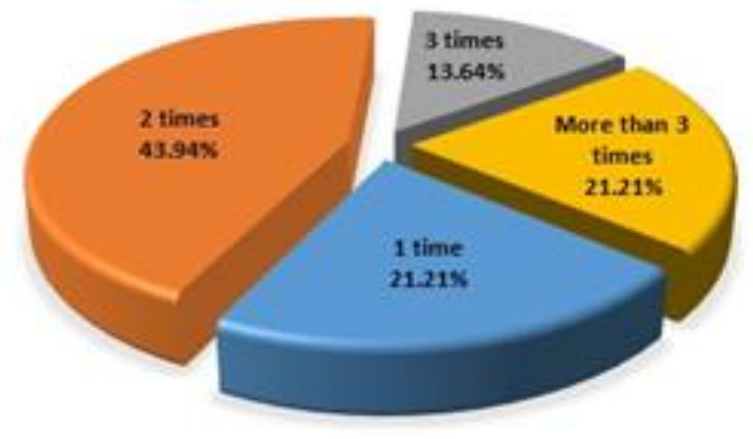

Figure 16. Answer this question „How many times a week you do physical exercises?"

To the question „How long is your physical exercises outside of the University" " half of the students $(50 \%)$ are practicing physical exercise up to 60 minutes, $36.36 \%$ up to 30 minutes and over 60 minutes are $13.64 \%$. For comparison in
2011, a study by G. Dyakova on the same issue, $50.4 \%$ trained up to 30 minutes, $38.7 \%$ to 60 minutes, $10.9 \%$ more than 60 minutes. The results are presented graphically in Figure 17.

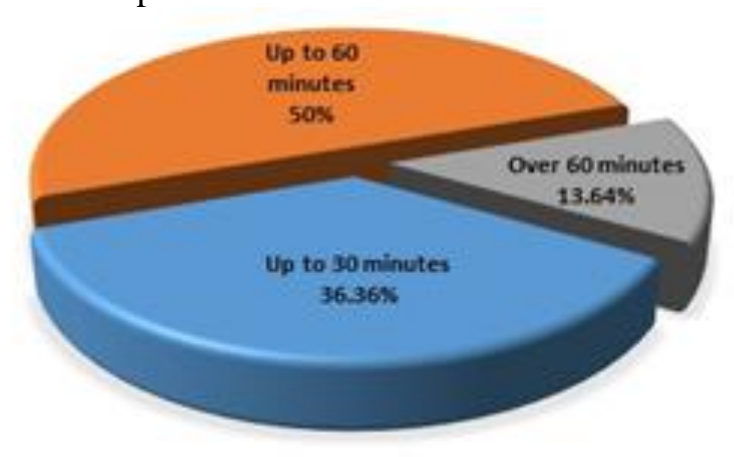

Figure 17. Answer this question „How many times a week you do physical exercises?" 


\section{CONCLUSIONS}

1. An increase the percentage of students who eat one and two times a day. There is also a high percentage of those who eat five or more times a day.

2. The relative share of students who consider healthy eating has decreased. The main cause for this is the lack of time and financial reasons.

3. Students consume less vegetables and fruits, and the relative share of consumption of fast food and soft drinks has increased. On their daily menu dominates pasta and meat products.

4. An increase of students who used pills and dietary supplements or had starved to reduce their body weight

5. It increases the percentage of students who spend sitting more than five hours a day.

6. More physical activity outside of the University.

\section{REFERENCES}

1. Dyakova, G., Studying attitudes of students to certain health factors. Sports and Science, $1 / 2011$.

2. Dyakova, G., Some views on the application of the theoretical knowledge in the preparation of the groups for fitness. Sports and Science, ISSN 1310-3303, 8, .p. 60-62, 1996.

3. https://www.thelancet.com/journals/lancet

4. Angelova, P., Dyakova, D., Study of anxiety in students, Personality. Motivation. Sports. Volume 18, NSA PRESS, Sofia, pp. 164-172, 2013.

5. Dyakova, G., Ivanova, V., Study of the dependence between the harmful hunger
PETKOV P.

habit and the physical fitness of students from the Trackia University. Trakia Journal of Sciences, ISSN 1312-1723, Vol. 6, N.2, p. 178-182), 2008.

6. Merdjanov, Ch., Can We Live Longer, Sofia, 2007.

7. Gatseva, P., Frequency of overweight and obesity in adolescents and assessment of their knowledge of healthy nutrition. Scripta periodica 10, 2007.

8. Dyakova, G., Research on Motor Interest and Nutrition in Students. Scientific Works - Rousse University, Volume 51, Series 8.2, 2012.

9. Dyakova, D., Study of Attitudes towards a Healthy Lifestyle of Students, Personality. Motivation. Sports., Volume 13, ISBN 978954-718-229-5, c. 235-242.), 2008.

10.Borisov, L., Nutrition and motor activity study in young people between 15 and 29 years of age, Sports and Science, 5/2017.

11.Milanova, P., Relationship Between Weight and Nutrition in Adolescents. Sports and Science, 5/2012.

12.Peltekova, I., Monitoring the Physical Activity in the Everyday Life of the Young Generation. ISBN 978-954-490-161-5, Ed. EKS-PRESS, Gabrovo, pp. 555-557, 2010.

13.Bozhkova, A., Risks and Benefits of Using Food Supplements Containing Alternatives to Ephedra Alkohoids in Sports. Medicine and Sport, ISSN 1312-5664, issue 1/2009), 2009.

14.Draganov, G., Bojkova, A., Application of Nutritional Supplements Containing Proteins and Amino Acids in the Comprehensive Training of Footballers. Medicine and Sports, ISSN 1312-5664, issue 4/2009, 2009. 